was sent to me for the purpose and I found it to have a specific gravity of 1008 and to give no reaction of sugar. The ferric-chloride test also gave no reaction, but a trace of albumin, corresponding with what I had noticed before I for awhile lost sight of the patient, was present. After the lapse of a few months I received a notification that death had taken place from general exhaustion.

(To be continued.)

\section{FRACTURE OF THE FIFTH CERVICAL VERTEBRA; RECOVERY.}

By W. E. F. TINLEY, M.D.DURH., M.R.O.S. ENG., SURGEON TO THE WHITBY PUBLIC DISPENSARY;

AND

A. R. JONES, M.R.C.S. ENG, L.R.C.P. LOND.

As recoveries from fracture of the spine in the cervical region are rare the following case may be of interest.

On August 2nd, 1902, a man in the employ of the NorthEastern Railway Company fell from a bridge on to a slope beneath, a distance of 40 feet, and then rolled on to the road below. He was carried home on a ladder and dragged up an awkward staircase on it. As the house was three miles from this town some considerable time elapsed before he was seen, when he was found to be in a semi-conscious condition with almost complete loss of power in the legs, some loss of power in the arms, and complaining of pain in the back of the neck. His pupils were contracted. He had no hæmorrhage from the nose, the ears, or the mouth. He was kept quiet and a sleeping draught was administered. In the evening he was conscious but otherwise his condition was unchanged. On the following morning he had retention of urine and a catheter had to be passed; he was then quite conscious and a fuller examination was possible. There was complete paralysis of the lower limbs with loss of the patellar and superficial reflexes. Well-marked priapism was present. The epigastric, cremasteric, and other superficial reflexes were absent. Respiration was difficult owing to paralysis of the intercostals. The right arm lay in the position of abduction; the elbow was flexed and supinated. The fingers and the wrists were motionless on the right side; this was less so on the left but in a day or two the loss of power was as complete on this side as on the right.

On August 6 th the patient began to have incontinence of urine in place of retention and as the nursing was not of the best bedsores began to develop in spite of all care. His temperature during the first few days varied from $101^{\circ}$ to $102^{\circ} \mathrm{F}$. The most tender spot on the spinal column was over the fifth vertebra, where there was an irregularity, but it was not thought advisable to move the head much to make further examination. The only medicinal treatment was the occasional administration of morphia, chloral, and bromide. He was kept perfectly quiet and his head was steadied with sandbags. He took liquid food fairly well but he had difficulty in swallowing and seemed afraid of "choking." His bedsores got much worse and his general condition became critical and a fatal result seemed to be inevitable unless he could be removed to some place where he could obtain good nursing. He was therefore removed to the Whitby Cottage Hospital three miles away. He was placed on a stretcher and through the window on to a scaffolding that was erected and he was carried by hand to Whitby, placed on a water-bed, and with good nursing the bedsores on the back began to improve but one on the right elbow gave much trouble and remained open till he got out of bed. The arms were flexed and could not be straightened owing to their spastic condition and the fingers were obstinately flexed.

For some months his condition remained very much the same but the superficial reflexes returned and he became extremely hypersensitive; his patellar reflexes were very much exaggerated and he developed ankle clonus. $\mathrm{He}$ complained of involuntary contractions of his leg muscles which gave him great pain when they came on. He was able to retain his urine until the urinal was brought but conld not retain his fæces until the nurse came to him. Abjut March he began voluntarily to move his feet; later he was able to raise his knees and in June to move bis arms a little. The faradic current was used for a short time each day and he had massage for the arms, the fingers, and the legs. He was allowed to sit up in bed in July and was put on a mattress instead of the water-bed and shortly afterwards he was lifted into a chair but could not help himself in any way. In August he was able to take a few steps with help and when he left the hospital in September he walked to a cab but with a distinctly spastic gait. The day before he was discharged the following was found to be his condition. He had good movement at the ankles, the knees, and the hips, and greatly increased knee-jerks; the superficial reflexes were normal ; the intercostal muscles still lacked power. He had control over his urine but occasional want of control over his motions. He was able to flex and to extend his fingers to some extent but some of the joints were quite ankylosed. The left shoulder and the elbow were capable of movement to almost the normal extent but his right elbow was nearly fixed at a right angle. He conld feed himself and hold a paper to read. The nutrition of the body was fair; that of the skin was good. Over the fifth cervical vertebra was a distinct boss of bone as large as a walnut and he carried his head bent forward and stiff.

When heard of recently the patient's condition was very much the same as when he left hospital. His recovery was to a large extent accounted for by the excellent nursing which he received from the nursing staff at the hospital as he was in a dreadful condition when he reached that institution.

Whitby.

\section{A CONFIRMATORY TEST FOR THE PRE- SENCE OF MECONIC ACID.}

By F. N. WINDSOR, B.A., M.B., B.C. Cantab, B. SC. VICT.,

CAPTAIN, I.M.S.; OFFICIAIING CHEMICAL EXAMINER TO THE GOVERNMENT OF THE PUNIAB.

IN cases of opium poisoning frequently the amount of meconic acid separable from organic matter is so small that it is difficult to determine whether addition of ferric perchloride causes a reddish tint or whether the colour is only yellow. In performing this test a "control" is always carried out with distilled water equal in volume to that of the suspected liquid. This volume is usually about three drachms and test-tubes of small calibre are used to obtain as long a column as possible to look through. Two drops of ferric perchloride solution (B.P.) are added to each tube and the colours are compared. If the reddish tint of the suspected liquid be not distinct then one drachm from the contents of each tube is boiled for 30 seconds. In each case the colour changes to a deep reddish-brown. If to each of the hot solutions four drops of dilute nitric acid (strength 1 in 5 ) or dilute hydrochloric acid (strength 1 in 7 ), preferably the former, be added the colour of the ferric meconate solution fades until in 12 hours the solution is colourless while that of the ferric perchloride (in which is a soluble hydroxide) is little or not at all affected.

The Removal of King's College Hospital to SOUTH LONDON. - The site of 12 acres, at present known as "The Sander's Estate," which has been presented to King's College Hospital in Soutb London, is at the foot of Denmark Hill, close to Camberwell Green, and in close proximity to the three railway stations of Denmark Hill, Loughborough Junction, and Camberwell New Road. In addition to this convenience the main electric tram lines run from Deptford, New Cross, Peckham, right through Camberwell Green, and a further line is now being laid down which will pass the doors of the new hospital, so that the situation is one rapidly and easily accessible from every district of South London. By reason of its position and extent the site affords an opportunity for the building of the most scientifically constructed institution of the kind in England, and it is very earnestly to be hoped that the appeal which is now being made for the $£ 300,000$ required to carry out this truly necessary scheme will meet with the hearty support of all generous benefactors throughout the metropolis. 